\title{
PROTOTYPE PENGUKURAN TINGGI DEBIT AIR PADA BENDUNG DENGAN MENGGUNAKAN SENSOR ULTRASONIK BERBASIS ARDUINO MEGA 2560
}

\author{
Hilmy Jawas ${ }^{1}$, N.M.A.E.D.Wirastuti ${ }^{2}$, Widyadi Setiawan ${ }^{3}$ \\ ${ }^{123}$ Program Studi Teknik Elektro, Fakultas Teknik, Universitas Udayana \\ Email: Hilmy jawas@yahoo.com ${ }^{1}$, dewi.wirastuti@unud.ac.id ${ }^{2}$, widyadi@unud.ac.id ${ }^{3}$
}

\begin{abstract}
ABSTRAK
Prototype pengukuran tinggi debit air pada bendung dengan menggunakan sensor ultrasonik berbasis arduino mega 2560 dirancang sistem deteksi banjir yang bekerja secara otomatis dengan cara mengetahui ketinggian (level) permukaan debit air bendung. Sistem pemantauan ketinggian permukaan air ini dilakukan dengan mengimplementasikan sensor ultrasonik berbasis Arduino mega 2560, yang akan mengetahui ketinggian permukaan air yang dibuat pada level-level tertentu. Perangkat prototype pengukuran tinggi debit air pada bendung dengan menggunakan sensor ultrasonik berbasis arduino mega 2560 ini terdiri dari Arduino Mega 2560, Sensor Ultrasonik HC-SR04, LCD 16 X 2, dan Buzzer. Arduino berfungsi untuk mengetahui nilai sensor dan memberikan output sesuai dengan pengukuran sensor tersebut. Sensor HC-SRO4 berfungsi untuk membaca ketingian air dari jarak $2 \mathrm{~cm}-300 \mathrm{~cm}$, ketinggian air ini ditampilkan pada LCD dan Modul suara Buzzer berfungsi untuk membunyikan alarm pada ketinggian $16 \mathrm{~cm}$ sampai $45 \mathrm{~cm}$.
\end{abstract}

Kata Kunci : Arduino Mega 2560, Buzzer, LCD 16 X 2, Sensor HC-SR04.

\section{ABSTRACT}

Prototype system for measuring the level of water debit on weir by using an Arduino mega 2560 based ultrasonic sensor. It is created for detecting flood system that works automatically by finding out the water level on the weir's surface. This water surface level monitoring system is conducted by implementing an Arduino mega 2560 based ultrasonic system, which will compute the water level created at certain levels. This prototype device for measuring the water level on weir by using Arduino mega 2560 based ultrasonic sensor consists of Arduino Mega 2560, HCSR04 Ultrasonic Sensor, $16 \times 2$ LCD, and Buzzer. Arduino serves to determine the sensor value and provides the output accordingly with the sensor measurement. HC-SRO4 Sensor functions to read the water level from a distance of $2 \mathrm{~cm}$ to $300 \mathrm{~cm}$, this water level would be displayed on the LCD and the sound from Buzzer is going to sound the alarm at an altitude of $16 \mathrm{~cm}$ to $45 \mathrm{~cm}$.

Keywords: Arduino Mega 2560, Buzzer, HC-SR04 Sensor, 16x2 LCD,

\section{PENDAHULUAN}

Ketinggian permukaan air merupakan suatu parameter yang sering kita pantau. biasanya pengecekan ketinggian air masih dilakukan secara manual, yaitu petugas melihat langsung pada alat ukur manual yang terpasang pada pintu air agar dapat mengetahui berapa ketinggian debit air pada bendung. Pengecekan tersebut dilakukkan pada kondisi cuaca apapun

Pada penelitian sebelumnya telah dirancang Sistem peringatan dini banjir terdiri dari beberapa komponen, dimana sensor merupakan salah satu komponen pentingnya. Pada sistem peringatan bencana banjir, sensor yang digunakan adalah sensor pendeteksi jarak yang mampu mendeteksi ketinggian permukaan air. Sensor yang digunakan dalam sistem peringatan bencana banjir adalah sensor HC-SR04 [1].

Dari paparan penelitian yang telah dilakukan sebelumnya, maka dibuat Prototype pengukuran tinggi debit air pada bendung dengan menggunakan sensor ultrasonik berbasis Arduino mega 2560 digunakan untuk monitoring ketinggian debit air pada bendung. Sensor ultrasonik dan data ketinggian air dapat dilihat pada display LCD (liquid crystal display) 16x2 yang terpasang pada alat dan buzzer digunakan untuk mengeluarkan suara 
alaram pada bendung ketika debit air bendung melebihi batas normal dan akan terjadinya banjir.

\section{KAJIAN PUSTAKA}

\subsection{Arduino Mega}

Arduino mega menggunakan chip Atmega 16u2 merupakan perangkat yang terdiri dari software dan hardware. Hardware Arduino mega sama dengan mikrokontroler pada umumnya hanya pada arduino ditambahkan penamaan pin agar mudah diingat. Software Arduino merupakan software open source sehingga dapat di download secara gratis[2].

\subsection{LCD (Liquid Crystal Display)}

Display elektronik adalah salah satu komponen elektronika yang berfungsi menampilkan suatu data, baik karakter,angka dan huruf ataupun grafik. LCD adalah salah satu jenis display elektronik yang dibuat dengan teknologi CMOS logic untuk menampilkan hasil kinerja alat[3].

\subsection{Sensor Ultrasonik}

Sensor Ultrasonik yaitu sebuah device transmiter dan receiver yang tersedia pada modul HC-SR04 ini mempunyai pin VCC, TRIG, ECHO dan GND. HC-SRO4 memiliki kinerja sama seperti radar yang baik dalam mendeteksi jarak atau ketinggian [4].

\subsection{Buzzer}

Buzzer adalah sebuah komponen elektronika dapat berfungsi untuk mengubah getaran listrik menjadi getaran suara. jadi buzzer juga terdiri dari kumparan yang terpasang pada diafragma kemudian kumparan tersebut dialiri arus hingga dapat menjadi elektromagnet, kumparan akan tertarik ke dalam atau keluar, tergantung dari arah aliran arus dan polaritas magnetnya[5].

\section{Metode Penelitian}

Penelitian dilakukan di Laboratorium Sistem Telekomunikasi Jurusan Teknik Elektro Fakultas Teknik Universitas Udayana.

\subsection{Perancangan Perangkat Keras}

Diagram blok dari prototype pengukuran tinggi debit air pada bendung dengan menggunakan sensor ultrasonik berbasis Arduino mega 2560 dapat dilihat pada Gambar 1.

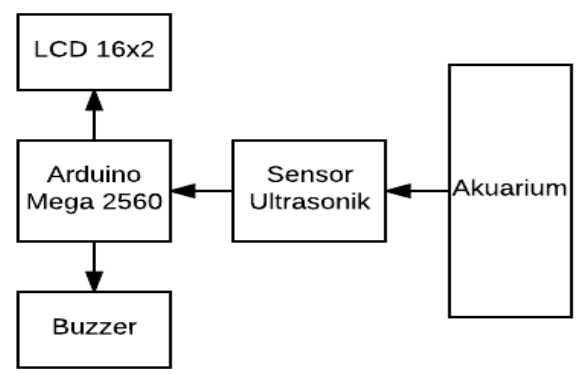

Gambar 1. Diagram Blok Pragkat Keras

Pada Gambar 1 dapat dilihat saat Akuarium menghasilkan Output berupa tinggi air yang di ukur oleh sensor ultrasonik menghasilkan nilai ukur dan diproses oleh Arduino mega 2560 dan data dapat ditampilkan pada layar LCD dan buzzer menandakan bahwa air melebihi dari batas normal.

\section{Hasil Dan Pembahasan}

\subsection{Realisasi Hasil Perancangan}

Realisasi Prototype Pengukuran Tinggi Debit Air Pada Bendung Dengan Menggunakan Sensor Ultrasonik Berbasis Arduino Mega 2560 dapat dilihat pada Gambar 2 dan Gambar 3.

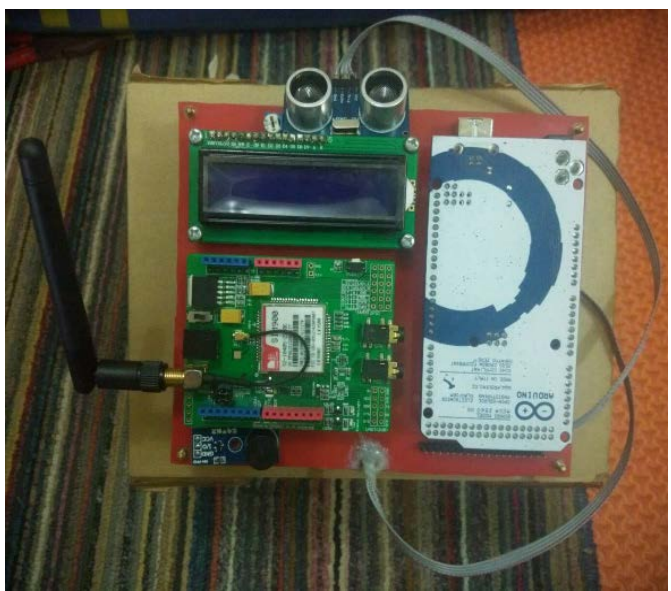

Gambar 2. Tampilan Prototype 


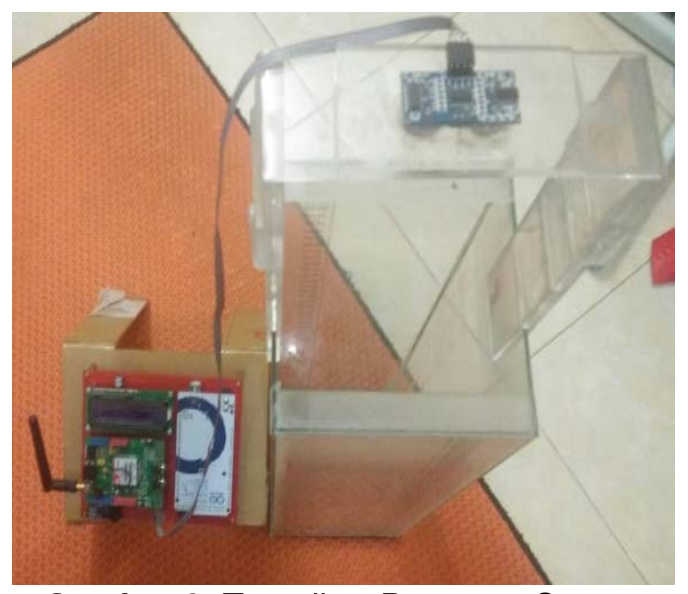

Gambar 3. Tampilan Prototype Secara Keseluruhan

\subsection{Pembahasan}

Pembahasan perangkat akan dilakukan pengujian sensor ultrasonik yang dapat mengukur ketinggian debit air pada bendung dan hasil akan dikirimkan melalui arduino untuk ditampilkan pada LCD.

\subsection{Pengujian Prototype}

Pengujian prototype Pengukuran Tinggi Debit Air Pada Bendung Dengan Menggunakan Sensor Ultrasonik Berbasis Arduino Mega 2560.

1. Pengujian pada kondisi normal

2. Pengujian pada kondisi siaga

3. Pengujian pada kondisi berbahaya

\subsubsection{Pengujian Pada Kondisi Normal}

Pengujian penelitian ini dilakukan Pada kondisi normal bekerja dengan sempurna mendapatkan hasil $0 \mathrm{~cm}$ sampai $15 \mathrm{~cm}$ pengukuran sensor akan ditampilkan pada LCD $16 \times 2$ yang terpasang pada prototype dan dapat dilihat pada Gambar 4.

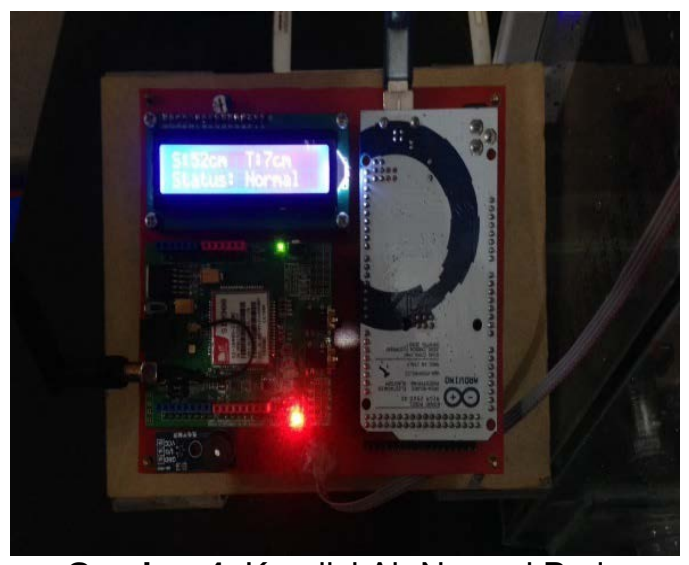

Gambar 4. Kondisi Air Normal Pada Tampilan LCD $16 \times 2$

Pada Gambar 4 dapat dilihat hasil pengukuran sensor ultrasonik pada tampilan LCD terdapat informasi tinggi sensor (S), tinggi air ( $T$ ) dan status bendungan. Hasil $T=7 \mathrm{~cm}$ menandakan kondisi air berstatus normal dan $\mathrm{S}=52 \mathrm{~cm}$ adalah tinggi sensor.

\subsubsection{Pengujian Pada Kondisi Siaga}

Pengujian penelitian ini dilakukan Pada kondisi siaga prototype dapat menampilkan nilai $16 \mathrm{~cm}$ sampai $20 \mathrm{~cm}$ dan akan menampilkan hasil pengukuran sensor pada LCD $16 \times 2$ dan buzzer akan berbunyi yang terpasang pada prototype dan dapat dilihat pada Gambar 5.

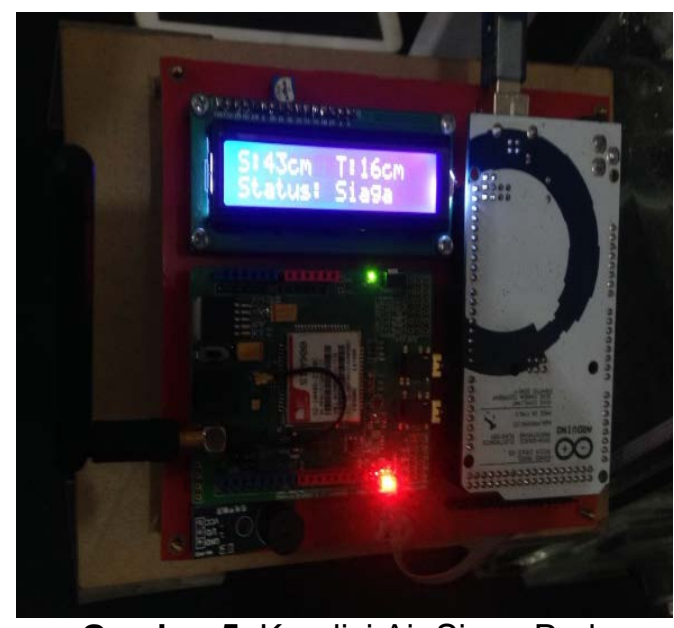

Gambar 5. Kondisi Air Siaga Pada

Tampilan LCD $16 \times 2$

Pada Gambar 5 dapat dilihat hasil pengukuran sensor ultrasonik pada tampilan LCD terdapat informasi tinggi sensor (S), tinggi air ( $T$ ) dan status 
bendungan. Hasil $\mathrm{T}=25 \mathrm{~cm}$ menandakan kondisi air berstatus siaga dan $\mathrm{S}=34 \mathrm{~cm}$ adalah tinggi sensor.

\subsubsection{Pengujian Pada Kondisi Bahaya}

Pengujian penelitian ini dilakukan Pada kondisi berbahaya prototype dapat menampilkan nilai $21 \mathrm{~cm}$ sampai $45 \mathrm{~cm}$ dan akan menampilkan hasil pengukuran sensor pada LCD $16 \times 2$ dan buzzer akan berbunyi yang terpasang pada prototype dan dapat dilihat pada Gambar 6.

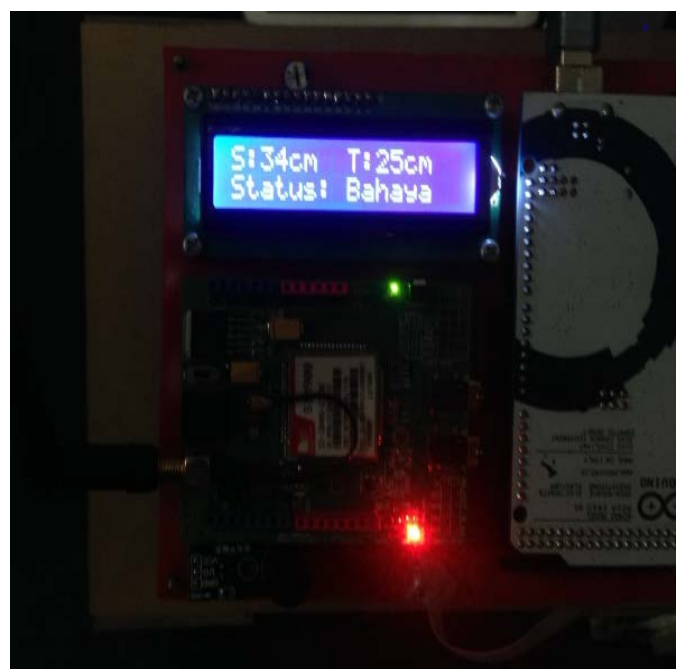

Gambar 6. Kondisi Air Bahaya Pada Tampilan LCD $16 \times 2$

Pada Gambar 6 dapat dilihat hasil pengukuran sensor ultrasonik pada tampilan LCD terdapat informasi tinggi sensor (S), tinggi air (T) dan status bendungan. Hasil $T=25 \mathrm{~cm}$ menandakan kondisi air berstatus siaga dan $\mathrm{S}=34 \mathrm{~cm}$ adalah tinggi sensor.

\section{Kesimpulan}

Dari pembahasan yang telah diuraikan sebelumnya,maka simpulan yang dapat diambil berdasarkan hasil pengujian dan pembahasan dalam prototype pengukuran tinggi debit air pada bendung dengan menggunakan sensor ultrasonik berbasis Arduino mega 2560 adalah sebagai berikut:

1. Pengukuran tinggi air dengan menggunakan sensor ultrasonik sudah dapat ditampilkan pada LCD. Pengukuran air dilakukan pada jarak 2 $\mathrm{cm}$ sampai $50 \mathrm{~cm}$ yang mendapatkan hasil baik sesuai dengan pengujian pada prototype.

2. Buzzer dapat bekerja dengan sempurna sesuai perintah aplikasi yang menandakan situasi bahwa tinggi debit air pada bendung melebihi batas normal agar warga sekitar dapat mengetahui ketinggiang air maupun informasi bencana banjir.

\section{Daftar Pustaka}

[1] A.Martalia,"Kalibrasi Sensor Ultrasonik $\mathrm{Hc}$-SrO4 Sebagai Sensor Pendeteksi Jarak Pada Prototipe Sistem Peringatan Dini Bencana Banjir".Proseding Seminar Nasional Fisika, Vol 5,Oktober 2015.

[2] E Mulyana., "Perancangan Alat Peringatan Dini Bahaya Banjir Dengan Mikrokontroler Arduino Uno R3".Citec Journal, Vol 1 No 3,Mei 2014.

[3] Sutono."Sistem Monitoring Ketinggian Air".Majalah IImiah UNIKOM, Vol 13, No 1,September 2013.

[4] Suryono,"Sistem Akuisis Data Komputer Pada Sensor Ultrasonic Ranger Untuk Pengukuran Level Muka Air".Berkala Fisika ,Vol 16 No 4, Oktober 2013.

[5] "Buzzer pasif for arduino data sheet," 